\title{
Duration of Commute Travel Changes in the Aftermath of Hurricane Sandy using Accelerated Failure Time Modeling
}

\author{
Eleftheria Kontou $^{a, b}$, Pamela Murray-Tuite ${ }^{a 1}$, Kris Wernstedt $^{c}$ \\ ${ }^{a}$ Department of Civil and Environmental Engineering, Virginia Tech, \\ 7054 Haycock Road, Falls Church, VA 22043, USA \\ ${ }^{b}$ Current Affiliation: Postdoctoral Researcher, Transportation and Hydrogen Systems Center, \\ National Renewable Energy Laboratory, \\ 15013 Denver West Parkway, Golden, CO 80401, USA \\ ${ }^{c}$ School of Public and International Affairs, Virginia Tech, \\ 1021 Prince Street, Alexandria, VA 22314, USA
}

\begin{abstract}
This paper used survey data from 397 commuters in the New York City area to determine the transportation-related disruptions and socio-demographic characteristics associated with the duration of home to work commute travel changes after Hurricane Sandy in 2012. The durations examined included those associated with working schedule/location alterations, home-to-work trip delays, telecommuting time, and the alteration of commuting patterns. Accelerated failure time fully parametric duration models, based on the Weibull distribution were used. The models' significant variables differed. Commuters with higher income or who were highly educated were more likely to prolong the time to return to normal working schedules and increase telecommuting duration. Longer commutes under normal circumstances (based on trip time) prolonged trip delays and the number of days that the commute was changed. Prolonged service recovery periods increased the duration of commute changes and delays, emphasizing the importance of timely transit service restoration. Policies like gas purchase restrictions were found to have trade-offs, since they can prolong the duration of commute changes and create queues at gas stations. Telecommuting can allow commuters to keep their productivity levels high during post-disaster periods.
\end{abstract}

Key words: Hurricane Sandy; commuter adaptation; transportation disruptions; traveler response; duration models

\footnotetext{
${ }^{1}$ Corresponding author. Tel.: +1 703538 3764; fax: +1 7035388450 .

E-mail addresses: murraytu@vt.edu (P. Murray-Tuite), Ria.Kontou@nrel.gov (E. Kontou), krisw@vt.edu (K. Wernstedt).
} 


\section{INTRODUCTION}

In 2012, Hurricane Sandy disrupted all motorized forms of transportation in the New York City (NYC) area. The transportation service recovery process was extensive and in some areas lasted for weeks. While restoration activities were taking place, transportation agencies and government officials implemented various strategies to make use of available assets, provide transportation connectivity, and manage demand. These strategies included high occupancy vehicle (HOV 3+) restrictions on several major bridges (Bloomberg, 2012b), "even/odd" policies restricting access to gasoline stations by license plate number (Bloomberg, 2012c), modified taxi and other for-hire passenger policies (Bloomberg, 2012a), special agreements with ferry providers, and free parking, bus service, and ferry service to locations in New York (NJ Transit, 2012). While the infrastructure and service adaptations and recovery can be tracked through public announcements (e.g., Kaufman et al., 2012), individual commuter behavior and adaptation are more difficult to capture.

To capture the changes commuters made and the duration of these changes, a telephone survey of NYC area commuters was conducted. The objective was to use the survey data to estimate duration hazard-based models and determine the parameters that have a statistically significant impact on the duration of commuter behavior changes that occurred in Hurricane Sandy's aftermath. The starting point for calculating the duration of the events associated with our study is Hurricane Sandy's landfall. Using accelerated failure time duration modeling, the authors account for the possibility that the likelihood of a commuting behavior change may change over time. After Hurricane Sandy, commuters needed to modify their behavior to adapt to altered transportation availability. As transportation agencies restored infrastructure and service, more choices became available, which may have allowed commuters to return to their normal schedules and commuting choices.

The specific factors examined in this study pertain to the: (1) elapsed time for commuters to return to normal schedules, (2) additional time commuters allocated for their commutes, (3) days commuters spent telecommuting, and (4) elapsed time for commuters to return to normal pre-Sandy patterns of commuting (making the trip), commute mode, commute time, and work location. As such, this paper sheds light on commuting-recovery time by analyzing the relationships between pre-Hurricane Sandy commuting behaviors, socio-demographic attributes, and post-Hurricane Sandy disruptions and the time to return to normal commute patterns.

The remainder of this paper is divided into five sections. Section 2 provides an overview of related literature and presents a series of hypotheses investigated in this work. Section 3 provides a brief overview of the data, Section 4 presents an overview of the modeling approach, and Section 5 discusses the results. The final section provides conclusions.

\section{LITERATURE REVIEW AND HYPOTHESES}

Commuters face transportation service disruptions from a variety of sources, including planned reconstruction, natural disasters, infrastructure failures and accidents, and terrorist attacks. For each of these disruptions, commuters must adapt their travel choices, within their abilities and resources, to the infrastructure and services available.

Previous studies indicated that the most commonly observed changes are route and departure time changes, especially for planned efforts such as the nine week reconstruction of I-5 "the Fix" (Mokhtarian et al., 2009), reconstruction of Boston's Southeast Expressway (Meyer, 1985), and reconstruction of Pittsburgh's I-376 (Hendrickson et al., 1982). For some unplanned 
events, such as earthquakes and bridge collapses, the availability of transit options allowed significant (albeit temporary) mode shifts to transit (Ardekani, 1992; Gray et al., 1990), while commuting in other such events showed little decrease in total travel demand and few commuters switching modes (Giuliano and Golob, 1998; Homeburger, 1990; Zhu et al., 2009). Work on travel post terrorist attacks appears similarly mixed. For example, Prager et al. (2011) showed significantly reduced trips on the London Underground following the 2005 bombings that supply factors, such as station closures, could not fully account for, and Rubin et al. (2007) documented changes in travel mode intentions after these bombings. Similarly, Ito and Lee (2005) showed reduced trips in air travel post 9/11, which appears offset in part by highway travel increases (Gigerenzer, 2006). In contrast to these findings, Lopez-Rousseau (2005) found decreases in both train and car travel after the Madrid train bombings in 2004.

Aside from studies pertinent to terrorist attacks, the literature has largely ignored changes in transit use post transport system disruption. Moreover, while a body of work has employed duration modeling and survival analysis to analyze the temporal dimension of everyday commuting behavior such as travel time and congestion duration (Anastasopoulos et al., 2012; Juan et al., 2011; Moore et al., 2013; Zhong et al., 2008; Zhong et al., 2012) and evacuation behavior (Fu and Wilmot, 2006; Hasan et al., 2013), no studies that we are aware of have examined predictors of event duration in the context of transit use after the onset of large-scale disruptive events. We address that gap in this paper by drawing on the covariates identified in duration analyses of non-transit behavior (e.g., gender, income, age, trip length). In particular, we draw on the extant literature to develop eight hypotheses which helped the modeling process by guiding the selection of potential variables.

Hypothesis 1: Women are more likely than men to have (a) longer commute alteration durations and $(b)$ lower home to work trip delays.

Gender's role in travel behavior and disasters is complex but often significant (e.g., (Enarson and Morrow, 1997; Fothergill, 1996)). Women appear more vulnerable than men during disaster recovery, often due to employment constraints and family care responsibilities (Cutter et al., 2003). We hypothesize that this will increase the number of days on which they alter their commute. In addition, women are more often responsible for re-creating a sense of security for children (Enarson et al., 2007), which may make them more likely than men to cancel commuting trips to be with their children, at least if school is not in session. To further support the first part of the hypothesis, Mokhtarian et al. (2009) found women more likely than men to use vacation days (cancel the work trip) during planned Interstate reconstruction (the "Fix").

Also associated with changing commutes, gender may influence the ability to change modes of transportation. Women on average earn less than men for many reasons, such as differences in education and type of job. About $40 \%$ of women do not have a day-shift job and women are more likely to have part time employment (Rosenbloom, 2006). These latter factors may affect the ability to use transit in a post-disaster/disruption scenario where special transit provision may focus on the peak periods. On the other hand, women are more likely to carpool than men for regular travel (Pucher and Renne, 2003) and their social networks may also help them form carpools after a major transportation-disrupting event. Taking all modes together for "the Fix," women were 16\% more likely to change modes than men (Mokhtarian et al., 2009). However, in an evaluation of individual transportation demand management (regular travel conditions), Rosenbloom and Burns (1993) found women less likely to change modes. While the effects of gender on mode changes are unclear, mode change is only one consideration in the commute alteration. 
Another part of altering the commute is the departure time. Again gender effects may be mixed. According to Sarmiento (2000) "women's work trip schedules tend to be more clustered around the peak; and this particularly true for women with children" (p. 47). Yet, Mokhtarian and Ye (2009) found women were more likely than men to avoid the peak hour and to change routes during reconstruction.

With regard to part (b) of the hypothesis, some convergence in labor force participation (Rosenbloom, 2006) has led to a decrease in the gender gap in terms of miles traveled and automobile use. Yet, even though significantly more women appear in the work force than in previous decades, the commute of the average woman differs from that of the average man (Crane, 2007; Jenkins et al., 2011), especially for married couples with children. For instance, employed married women have more variability in daily trip frequencies than their male counterparts (Sarmiento, 2000), partly due to more child-chauffeuring (Liu et al., 2012) and care giving (Johnston Anumonwo, 1998; Morrow, 1999) responsibilities, and these women make more household-serving trips such as grocery shopping (Crane and Takahashi, 2009; Mauch and Taylor, 1997; Rosenbloom, 2006). These additional responsibilities may also be related to the likelihood of using particular transportation modes. While men tend to travel longer distances (Crane, 2007), mothers are more likely to drive to work than fathers or women without children and greater numbers of and younger children cause women to be even more likely to drive than to use alternate modes (Rosenbloom and Burns, 1994). With the transit disruptions associated with Hurricane Sandy, we expect that automobile users experienced lower commuting delays.

Hypothesis 2: The number of children in a household is (a) positively associated with the days of commute alteration and $(b)$ negatively associated with the telecommuting duration.

Following the discussion for hypothesis 1, household composition affects travel choices under normal conditions. Transit may not be convenient for both single-parent and dual-parent workers with family/household responsibilities (Gould and Zhou, 2009). A greater number of children also places a greater economic burden on parents (Morrow, 1999) and encourages at least one parent to return to work as soon as possible. However, the other parent may have a greater number of days of commute changes (hypothesis 2a). In addition, a greater number of young children, can make it difficult to work at home (telecommute - hypothesis $2 \mathrm{~b}$ ), especially when schools or daycare centers are closed.

Hypothesis 3: Day care/school closure is positively associated with (a) work schedule-location change duration, (b) telecommuting duration, and (c) commute alteration duration.

The time span between the onset of an event and the return to work in a household with children may be influenced by the ability of the children to return to school or daycare. Parents often stay with their children when schools are closed rather than leaving them unattended (Cutter et al., 2000), which may encourage telecommuting (hypothesis 3b). Lack of child care may especially hinder the return to work of women after a disaster (Enarson et al., 2007) (hypothesis 3c). School and day care closures may also affect departure times (Kontou and Murray-Tuite, 2014) and, thus, work schedules (hypothesis 3a).

Hypothesis 4: Higher income is positively associated with (a) longer telecommuting time, (b) more days of commuting alteration, and (c) work schedule-location change.

Higher income communities have a greater ability to absorb and recover from damage/losses (Cutter et al., 2003). Similarly, at the household level, we posit that higher income households 
have more resources and options that allow more commute alternatives. For example, white collar jobs are more likely to offer flexibility such as telecommuting (hypothesis 4a), and a higher proportion of higher income households own a personal vehicle that allow route changes (hypothesis 4b). Higher incomes also allow transportation mode changes on transit as well as changes in departure times (hypothesis 4c). Also correlated with income, education factors may have an association with commuting alternatives - and are correlated with income - and we consider education as a control variable.

Hypothesis 5: Peak hour return commute is (a) negatively associated with telecommuting duration, (b) positively associated with home to work delays, and (c) positively associated with commute alteration duration.

A peak hour return commute somewhat implies a typical work day and possibly a lack of flexible schedule, which could be negatively associated with telecommuting (hypothesis 5a). Commuting during the peak implies congestion, which could be more severe during disruptions (hypothesis $5 \mathrm{~b}$ ) and lead to seeking ways to avoid the congestion through alternate commute options (hypothesis 5c).

Hypothesis 6: Older commuters telecommute for a longer period than younger telecommuters. We expect that teleworking options will encourage employees to work in alternative settings until the transportation services have been more fully restored so as to avoid unproductive, long commutes. Older commuters are expected to be more likely to have flexible schedules and telecommuting options than younger commuters.

Hypothesis 7: Having a damaged home is associated with longer durations of commuting changes.

Hurricane Sandy damaged or completely destroyed over 650,000 housing units in New York and New Jersey (Weselcouch, 2013; Blake et al., 2013). Commuters whose homes were damaged faced the need to repair their homes (possibly canceling commutes) and balance work and home responsibilities.

Hypothesis 8: The presence of gasoline purchase restrictions is positively associated with an increase in the duration of commuting changes.

Gasoline purchase restrictions are anticipated to encourage commute changes, particularly shifting transportation modes. They may also have induced queues at gas stations which could affect routing decisions, particularly if queues spilled back onto roadways (indicated by the media (Caruso, 2012; Harris, 2012)).

\section{DATA}

The data were collected through a January 2013 telephone-based survey of residents in New York, New Jersey, and Pennsylvania counties in the New York metropolitan area. This effort employed an independent survey research firm, who purchased valid call records for roughly 4,600 households in the metropolitan area. Of these households, approximately 34 percent refused to participate and 57 percent proved unreachable (no answer, busy, no callbacks), yielding 397 respondents in our sample (Kontou et al., 2016). This represents a 16 percent response rate, based on the proportional allocation method for calculating the eligibility rate of 
the unreachable telephone numbers (Smith 2009; American Association for Public Opinion Research 2015).

The questionnaire gathered information related to socio-demographic factors such as gender, age, and household income, as well as normal commuting patterns, such as commute mode and commute time, commuting behavior in the aftermath of the hurricane the durations of commuting changes, and the disruptions and temporary transportation services faced by the respondent. Our sample consisted of 397 commuters who provided consistent and complete responses.

Table 1 presents the independent variables used in the duration modeling and descriptive statistics and is updated from a previous study version (Kontou et al., 2016). In terms of sociodemographic characteristics, $58 \%$ of the sample answering the question were female, indicating an oversampling compared to Census statistics (47.92\% for the NYC Metropolitan Area) (U.S. Census Bureau, 2012); 81\% of the respondents were born in the US (vs. 69.18\% from Census estimates). The average number of children under 15 years old in the household was approximately 1 . Mean household annual income was fairly high at $\$ 108,000$, with a standard deviation over \$60,000; Census estimates of the NYC Metropolitan Area mean income for the 2012 American Community Survey (1-year estimate) was $\$ 79,037$. Related to this relatively high income, $82 \%$ of the participants had college degrees, compared to Census reports that 9.31\% of NYC Metropolitan Area adults have a bachelor's degree or above (U.S. Census Bureau, 2012). Approximately 53\% of our sample commuted to work by car compared to $57 \%$ by Census estimates. 
TABLE 1 Summary Statistics of the Independent and Dependent Variables

\begin{tabular}{|c|c|c|c|c|c|}
\hline Variables & $\begin{array}{l}\text { Sample } \\
\text { Size }\end{array}$ & Mean & $\begin{array}{l}\text { Standard } \\
\text { Dev. }\end{array}$ & Min & Max \\
\hline \multicolumn{6}{|l|}{ Independent } \\
\hline Gender: female 1 , otherwise 0 & 397 & 0.58 & 0.49 & 0 & 1 \\
\hline Age (in years) & 355 & 46.61 & 13.1 & 18 & 83 \\
\hline Born in the United States: 1 yes, 0 otherwise & 395 & 0.81 & 0.39 & 0 & 1 \\
\hline Income in thousand \$ & 283 & 107,694 & 61,714 & 5,000 & 200,000 \\
\hline Education: college and above 1 , otherwise 0 & 392 & 0.82 & 0.39 & 0 & 1 \\
\hline Number of children under the age of 15 in the household & 391 & 0.64 & 0.97 & 0 & 5 \\
\hline Telecommuting: 1 if it is an option, 0 otherwise & 393 & 0.24 & 0.43 & 0 & 1 \\
\hline \multicolumn{6}{|l|}{ Normal commute period } \\
\hline Commute mode automobile: 1 yes, 0 otherwise & 395 & 0.53 & 0.50 & 0 & 1 \\
\hline Commute mode transit: 1 yes, 0 otherwise & 397 & 0.45 & 0.49 & 0 & 1 \\
\hline Commute time from work to home (in minutes) & 391 & 37.52 & 25.21 & 15 & 95 \\
\hline $\begin{array}{l}\text { Commute from work-to-home during peak hours: } 1 \text { yes, } 0 \\
\text { no (peak } 4 \text { PM to } 8 \text { PM) }\end{array}$ & 363 & 0.771 & 0.42 & 0 & 1 \\
\hline \multicolumn{6}{|l|}{ Post Hurricane Sandy commute period } \\
\hline $\begin{array}{l}\text { Affected by carpool restrictions at the Lincoln Tunnel, } \\
\text { Brooklyn, Manhattan, Queensboro and Williamsburg } \\
\text { bridges: } 1 \text { yes, } 0 \text { no }\end{array}$ & 394 & 0.09 & 0.28 & 0 & 1 \\
\hline Affected by gasoline restriction policies: 1 yes, 0 no & 396 & 0.51 & 0.5 & 0 & 1 \\
\hline Affected by taxi policies and HOV3+: 1 yes, 0 no & 394 & 0.046 & 0.21 & 0 & 1 \\
\hline $\begin{array}{l}\text { Affected by service disruptions on the } \mathrm{NJ} \text { transit bus or } \\
\text { rail: } 1 \text { yes, } 0 \text { no }\end{array}$ & 395 & 0.053 & 0.22 & 0 & 1 \\
\hline Home damaged: 1 yes, 0 no & 338 & 0.198 & 0.4 & 0 & 1 \\
\hline Day-care/school for children closed/damaged: 1 yes, 0 no & 219 & 0.826 & 0.38 & 0 & 1 \\
\hline \multicolumn{6}{|l|}{ Dependent Variables } \\
\hline $\begin{array}{l}\text { (1) Time to return to normal working schedule and } \\
\text { location after Hurricane Sandy (days) returnnormal }\end{array}$ & 292 & 7.33 & 9.72 & 1 & 116 \\
\hline $\begin{array}{l}\text { (2) Additional commute time for home-to-work trip in } \\
\text { Hurricane Sandy's aftermath (minutes) commutedelay }\end{array}$ & 202 & 51.10 & 49.75 & 3 & 320 \\
\hline $\begin{array}{l}\text { (3) Time telecommuting in the post-Hurricane Sandy } \\
\text { period (days) telecommute }\end{array}$ & 333 & 1.05 & 2.01 & 0 & 8 \\
\hline $\begin{array}{l}\text { (4) Time of alteration of commuting patterns because of } \\
\text { disruptions in the post-Hurricane Sandy period (days) } \\
\text { alteration }\end{array}$ & 393 & 6.69 & 7.43 & 0 & 30 \\
\hline
\end{tabular}

The dependent variables included:

- alteration - duration of the alteration of commute patterns (in days),

- commutedelay - duration of the commuters' delays between home and work on at least one day after Hurricane Sandy struck (in minutes),

- telecommute - duration of the days of telecommuting in the aftermath of Hurricane Sandy, and

- returnnormal - the time (days) to return to the normal working schedule.

Figure 1 portrays the survival probability $\mathrm{P}(\mathrm{t}>\mathrm{T})$ for the duration of the events. The baseline for the duration parameters measured in days was the occurrence of Hurricane Sandy, 
while the baseline of the additional time added during the commute was the departure time leaving home for work one day after Hurricane Sandy struck.

Figure 2, derived from information from the media and the area's transportation agencies, presents a timeline of key pre- and post-Hurricane Sandy activities and decisions. As the timeline indicates, transit and bridge closure occurred before Hurricane Sandy struck the area and additional restrictions and closures subsequently appeared, and then were lifted. By November 19, NYC and MTA transit service was almost fully restored, but it took an additional two weeks for New Jersey Transit to recover.

(1)

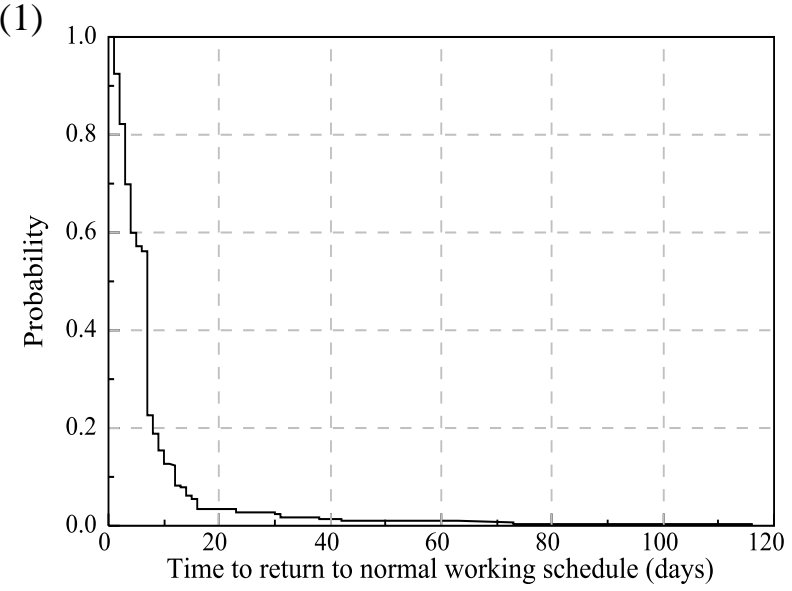

(3)

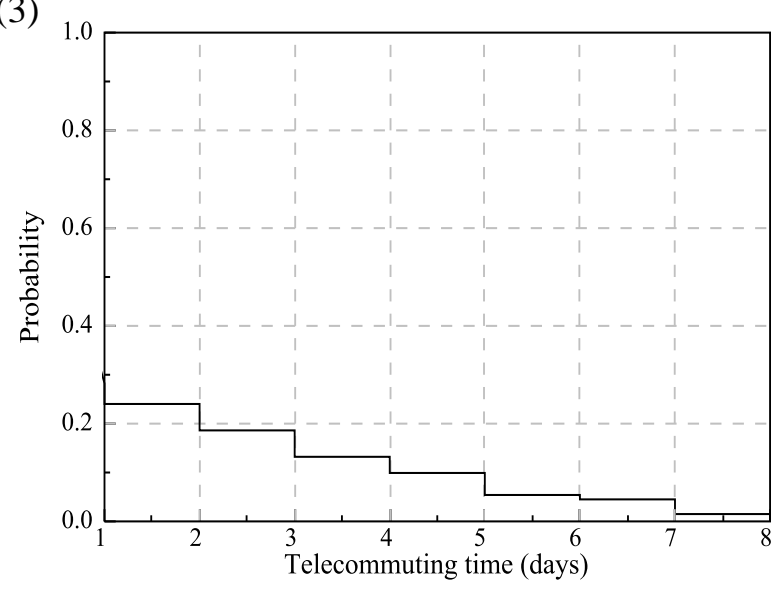

(2)

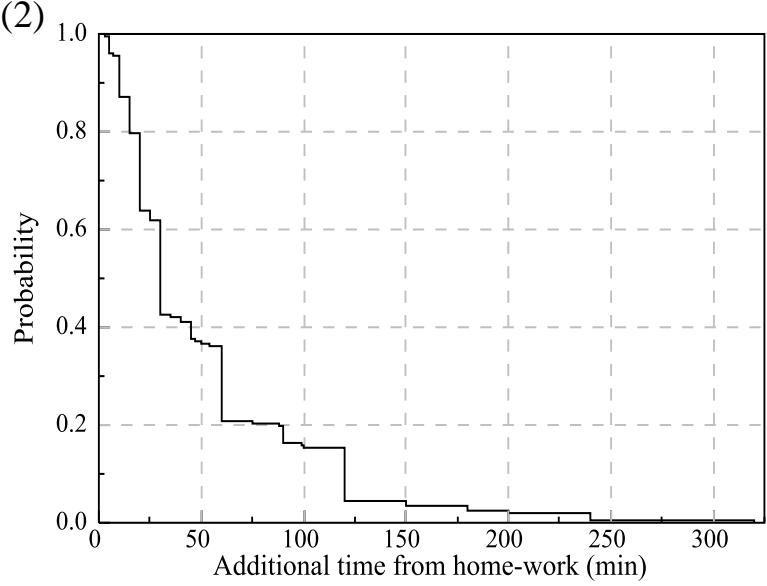

(4)

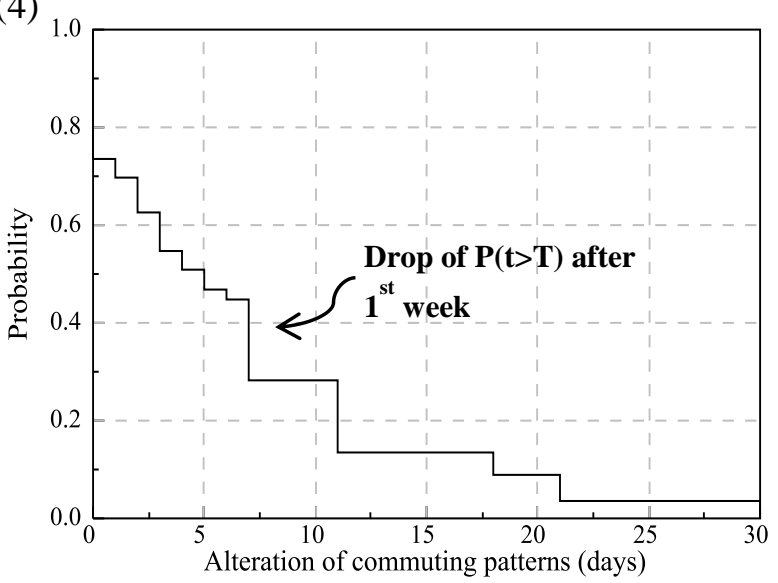

FIGURE 1 Survival probabilities $P(t>T)$ in the aftermath of Hurricane Sandy

A visual comparison of Figure 2's timeline, the summary statistics in Table 1, and the survival probabilities shown in Figure 1 suggested an association between recovery events and our commute alteration dependent variables. For example, the mean value of the variables returnnormal (1) and alteration (4), which was approximately 7 days, indicated that many returned to their usual commuting habits roughly within a week after Hurricane Sandy, which was consistent with the partial restoration of MTA's subway service and lifting of HOV3+ restrictions in the timeline. The mean value of the variable telecommute (3) in our sample of 1 day suggested a possible association with the complete absence of transit and the closures of the Brooklyn-Battery and the Holland tunnels on October 30, 2012. 
10/27/12

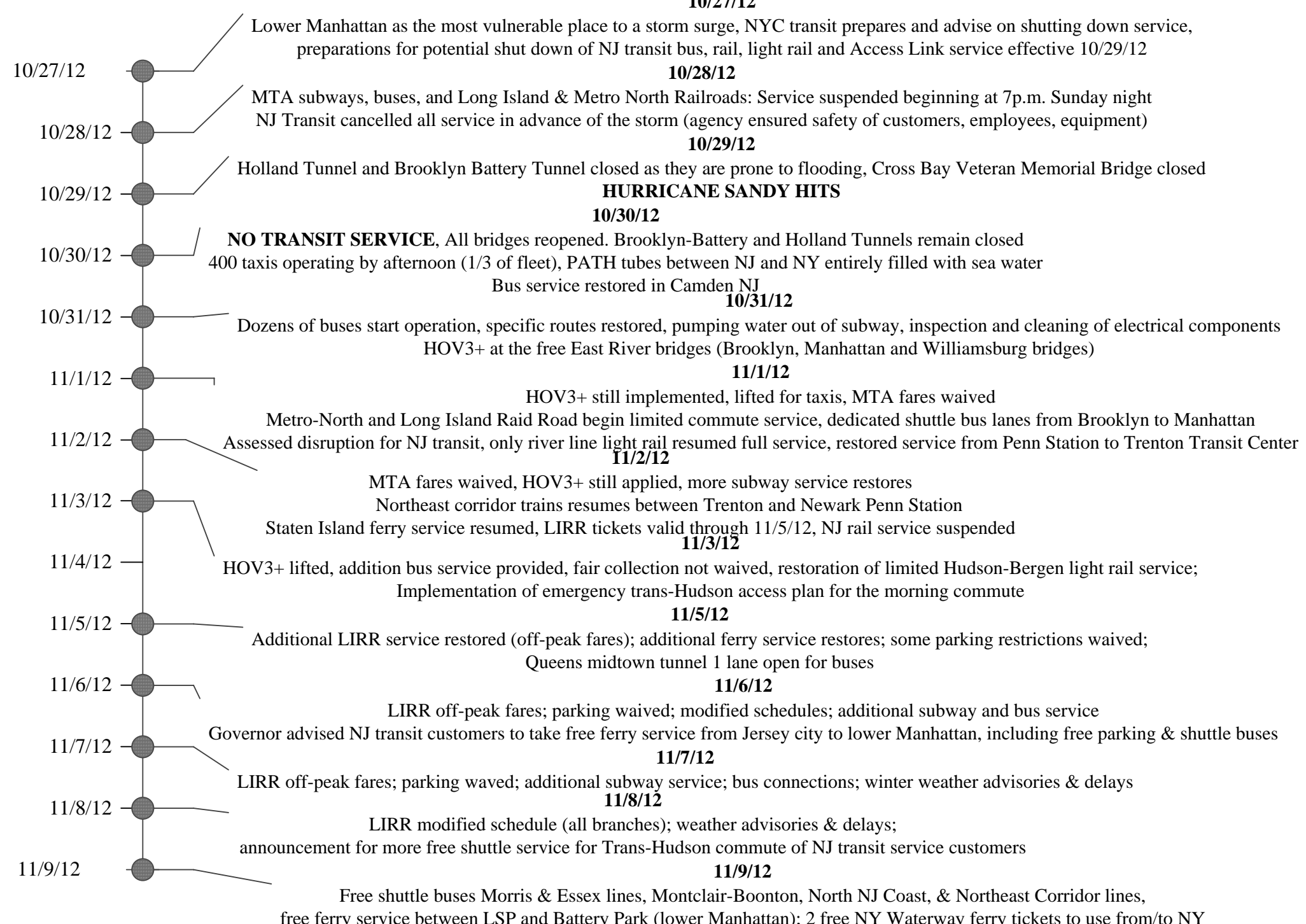

free ferry service between LSP and Battery Park (lower Manhattan); 2 free NY Waterway ferry tickets to use from/to NY

\section{FIGURE 2 NYC, MTA and NJ milestones in the first two weeks of recovery from Hurricane Sandy}




\section{FULLY PARAMETRIC DURATION MODELING}

To investigate significant factors that affected the duration of the commute alteration patterns in the aftermath of Hurricane Sandy, we chose the Weibull distribution for our hazard model, as it appears to be the most widely used in duration studies (Hensher and Mannering, 1994). The distribution provides a flexible means of capturing duration dependence (positive, negative, or none) and allows monotonically increasing $(P>1)$, decreasing $(P<1)$, or constant $(P=1)$ hazard rates (Anastasopoulos et al., 2012; Washington et al., 2011). Equation (1) shows its density function, with parameters $\lambda>0$ and $P>0$.

$$
f(t)=\lambda P(\lambda t)^{P-1} \mathrm{e}^{\left[-(\lambda t)^{P}\right]}
$$

The hazard function appears as equation (2):

$$
h(t)=\lambda P(\lambda t)^{P-1}
$$

and the accelerated failure time (AFT) model is given in equation (3):

$$
\log (T)=\beta_{0}+\beta_{1} x_{1}+\beta_{2} x_{2}+\cdots+\beta_{j} x_{j}+\delta \varepsilon
$$

where

$T$ is the failure time, denoting time elapsed since commute patterns changed from normal, $\beta_{0}, \ldots, \beta_{j}$ represent the accelerator estimators of the duration model, $x_{1}, \ldots, x_{j}$ represent the independent variables, and

$\varepsilon$ is the stochastic disturbance term with type- 1 extreme value distribution scaled by $\delta\left(\delta=\frac{1}{P}, P>0\right)$.

The accelerated failure time coefficients provide information about survivorship in the survival analysis. The exponential of each of the independent variables' coefficients (Hensher and Mannering, 1994) is the factor that could be translated to the increase or decrease of the time that elapsed by $e^{\beta_{j}}$ for each group.

Our purposeful covariate selection approach (Hosmer et al., 2011) started by introducing all of the variables to the model to evaluate the effect and statistical significance of each variable. We then examined the inter-correlation parameters between the independent variables through the correlation matrix and incorporated those that had significant importance, based on the pvalues and the soundness (based on expectations and reasonability) of each variable, removing insignificant variables in a stepwise fashion based on the results of the log-likelihood $\chi^{2}$ tests. The likelihood ratio L-R test of goodness of fit of one model compared to the previous one in shown in equation (4):

$$
L R: \chi^{2}=-2\left[L L\left(\beta_{\text {full }}\right)-L L\left(\beta_{\text {reduced }}\right)\right]
$$

where $L L\left(\beta_{\text {full }}\right)$ is the log likelihood at convergence for the full model and $L L\left(\beta_{\text {reduced }}\right)$ is the $\log$ likelihood at convergence for the reduced model. 


\section{RESULTS}

During the stepwise modeling process, retained variables not only need to meet statistical tests of significance, but they also should be potentially explained by the sequence of events in the postHurricane Sandy response and recovery period. Table 2 presents the final models and we discuss the results for each of the dependent variables in the following four subsections. 
TABLE 2 Estimates of accelerated failure time duration models

\begin{tabular}{|c|c|c|c|c|c|c|c|c|}
\hline \multirow{2}{*}{$\begin{array}{l}\text { Duration of: } \\
\text { Independent Variable }\end{array}$} & \multicolumn{2}{|c|}{$\begin{array}{c}\text { Work schedule- } \\
\text { location change } \\
\text { (days) } \\
\text { returnnormal }\end{array}$} & \multicolumn{2}{|c|}{$\begin{array}{c}\text { Home to work trip } \\
\text { delays (minutes) } \\
\text { commutedelay }\end{array}$} & \multicolumn{2}{|c|}{$\begin{array}{c}\text { Telecommuting time } \\
\text { (days) } \\
\text { telecommute }\end{array}$} & \multicolumn{2}{|c|}{$\begin{array}{c}\text { Commute alteration } \\
\text { (days) } \\
\text { alteration }\end{array}$} \\
\hline & Coefficient & L-R $\chi^{2}$ & Coefficient & L-R $\chi^{2}$ & Coefficient & L-R $\chi^{2}$ & Coefficient & L-R $\chi^{2}$ \\
\hline Intercept & 0.89 & & 3.59 & & 1.37 & & 1.70 & \\
\hline Female (binary) & & & 0.08 & 0.52 n.s. & & & -0.14 & 1.15 n.s. \\
\hline Born in States (binary) & 0.38 & $6.62 * *$ & & & & & & \\
\hline Age in years(continuous) & & & & & -0.02 & $5.59 * *$ & & \\
\hline Children $<15$ yo (continuous) & & & & & 0.02 & 0.16 n.s. & -0.01 & 0.03 n.s. \\
\hline Income in thousand $\$$ (continuous) & $1.79 \mathrm{E}-08$ & 0.99 n.s. & & & $8.15 \mathrm{E}-06$ & $20.47 * * *$ & $1.28 \mathrm{E}-06$ & 2.23 n.s. \\
\hline College and above (binary) & 0.43 & $4.31 * *$ & & & & & & \\
\hline Auto commute (binary) & & & -0.42 & $10.09 * * *$ & & & & \\
\hline Transit commuters (binary) & 0.30 & $3.43^{*}$ & & & & & & \\
\hline $\begin{array}{l}\text { Time of commute trip in minutes } \\
\text { (continuous) }\end{array}$ & & & 0.01 & $15.36^{* * * *}$ & & & 0.004 & $5.80 * *$ \\
\hline Peak hour work to home (binary) & & & 0.12 & 0.41 n.s. & -0.62 & $8.32 * * *$ & -0.16 & 0.98 n.s. \\
\hline Telecommuting (binary) & 0.35 & $3.54 *$ & & & & & & \\
\hline Gasoline restrictions (binary) & & & & & & & 0.24 & $5.03 * *$ \\
\hline Carpool restrictions bridges (binary) & & & 0.35 & $4.66 * *$ & 0.49 & $6.38 * *$ & & \\
\hline Taxi multiple riders policy (binary) & & & & & 0.62 & $6.37 * *$ & & \\
\hline NJ disruptions (binary) & 0.74 & $6.49 * *$ & & & 0.35 & $4.93 * *$ & 0.36 & $3.04 * *$ \\
\hline Home damaged (binary) & 0.36 & $3.31 *$ & & & & & 0.14 & 1.20 n.s. \\
\hline Daycare/school closure (binary) & 0.08 & 0.15 n.s. & & & 0.03 & 0.02 n.s. & 0.04 & 0.03 n.s. \\
\hline $\begin{array}{l}\text { (Children < } 15 \text { yo-1.09524)*(day care } \\
\text { closed (binary)-0.83673) }\end{array}$ & & & & & -0.28 & & & \\
\hline$\delta$ & 0.81 & & 0.74 & & 0.34 & & 0.69 & \\
\hline $\mathrm{P}=1 / \delta$ & 1.24 & $>1$ & 1.35 & $>1$ & 2.98 & $>1$ & 1.46 & $>1$ \\
\hline$-2 *$ LogLikelihood & 792.07 & $38.2 * * *$ & 1746.9 & $56.47 * * *$ & 133.88 & $26.96 * *$ & 1121.17 & $23.42 * * *$ \\
\hline Akaike's information criterion (AIC) & 813.842 & & 1761.54 & & 165.312 & & 1137.995 & \\
\hline Bayesian information criterion (BIC) & 841.121 & & 1783.36 & & 174.462 & & 1162.843 & \\
\hline Sample Size & 135 & & 183 & & 40 & & 183 & \\
\hline
\end{tabular}

Note: The significance symbols are $*$ for $p<=0.1, * *$ for $p<=0.05$ and $* * *$ for $p<=0.01$.

Robust errors were used in the estimation. 


\subsection{Time to returning to normal working schedule and location (returnnormal)}

Survey participants defined the date that they returned to normal working schedules and locations, with the responses ranging from 1 day to 116 days and a mean and standard deviation of 7 days and 10 days, respectively, as shown in Table 1. The model's extreme parameterization factor of the Weibull distribution $\delta=0.805$ (Table 2) translates to a shape parameter of $P=1.24>1$, suggesting that the hazard rate increased with duration. Thus, the amount of time left until returning to normal schedules and locations decreased as the duration increased.

Hypotheses 3(a) and 4(c) were not supported; daycare/school closures and higher income earnings were not necessarily associated with the work schedule/location change duration, as indicated by the associated variables being statistically insignificant.

The results indicated that commuters who had the option of teleworking spent $41 \%$ $\left[\left(e^{0.347}-1\right) \cdot 100\right]$ more time to return to a normal working schedule compared to commuters without this option, controlling for other personal and commute characteristics. Zhu (2013) found that telecommuting altered the commute frequency during normal periods. This variable's significance suggested teleworking has a significant impact during hazard recovery periods, possibly leading to maintaining the working force's productivity (assuming that electricity and telecommunications are available) and prolonging the time to return to normal commuting.

Variables other than those involved in the hypotheses were significant. For the group of commuters who were born in United States, returnnormal increased by an acceleration factor of $1.47\left(e^{0.383}\right)$, compared to commuters who were foreign born. For commuters who obtained college degrees, returnnormal increased by an acceleration factor of $1.53\left(e^{0.431}\right)$, compared to those with lower education levels. Besser et al. (2008) suggested that less education was strongly associated with lower commute time and possibly indicated usage of alternative commuting modes, such as bicycles, suggesting that they live closer to their working locations. Commuters who had college degrees, based on our dataset, had higher salaries; average annual income for the college graduates was approximately $\$ 117,000$ but for those who lacked a college degree, the average was $\$ 71,000$. Out of the college graduates, $15 \%$ normally used more than one mode to commute, their travel time was greater (36.3 minutes compared to approximately 30 minutes for not college graduates), and $63 \%$ indicated that at some point in the aftermath of Hurricane Sandy their work was closed. There might be a spatial implication related to the workplaces of the highly educated commuters. The Lower Manhattan area had to recover from damage, leading workplaces situated there, such as Wall Street, to be closed (Condon and Rothwell, 2012; Trotta, 2012).

Commuters using New Jersey Transit's bus and rail system (which, as noted earlier, suffered a greater period of disrupted service) experienced a nearly $109 \%\left[\left(e^{0.739}-1\right) \cdot 100\right]$ longer period before returning to a normal work schedule and location compared to non-New Jersey Transit commuters.

Commuters whose homes were damaged during Hurricane Sandy also appeared more likely to have a more prolonged period of work schedule and location changes, approximately $42 \%\left[\left(e^{0.356}-1\right) \cdot 100\right]$ higher than others.

Commuters who normally rode transit were $35 \%\left[\left(e^{0.299}-1\right) \cdot 100\right]$ more likely to face greater periods of work schedule/location changes than others. 


\subsection{Duration of commuters' home-to-work trip delay (commutedelay)}

The commute delay represents the maximum amount of additional time for a trip from home to work on at least one day in Hurricane Sandy's aftermath. The AFT model was developed on the sample of commuters who reported delays on the trip from home to work. The reported delays ranged from 3 minutes to 5.33 hours, with an average delay of 51.1 minutes and a standard deviation of 49.78 minutes (Table 1). The extreme parameterization factor of $\delta=0.74$ (Table 2) and the shape parameter $P=1.35>1$ of the Weibull distribution suggested that the hazard rate of this dependent variable also increased with duration.

The two variables (gender and having a peak period return commute) hypothesized to be significant in this model were insignificant, failing to support hypotheses 1 (b) and 5(b). However, several other variables were significant, as indicated in Table 2. The delay was $34 \%$ $\left[\left(1-e^{-0.417}\right) \cdot 100\right]$ lower for those who normally commuted exclusively using their personal automobiles compared to commuters using other modes. The severe damages and absence of service for the transit network caused at least the transit dependent population to encounter greater commute delays. Alternative mode users are potentially more vulnerable when it comes to transportation disruptions in the disaster recovery period.

The home-to-work delay time increased for those who normally commuted for a longer time, with a one minute increase in the normal commute time increasing delay by an accelerator factor of $1.009\left(e^{0.009}\right)$. Commuters who traveled for a longer time were more likely to encounter greater delays and potentially faced more than one disruption. They may also have used more than one mode to reach their work locations. The mean delay for 28 commuters who normally used more than one transportation mode and indicated that they faced delays was 66.7 minutes with a standard deviation of 61.4 minutes, a minimum of 10 minutes and a maximum of 320 minutes. For the 174 commuters who used only one transportation mode, the mean of the delays they faced was 48.6 minutes with a standard deviation of 47.3 minutes; the minimum and the maximum delays were 3 and 240 minutes. Thus, users of two or more modes experienced greater delays.

Finally, the delay was $42 \%$ longer $\left[\left(e^{0.353}-1\right) \cdot 100\right]$ for those who dealt with carpool restrictions on bridges compared to those who did not. Even though the HOV3+ measure was imposed to increase throughput by increasing each automobile's occupancy, this result indicated that the measure adversely affected the commute for some by increasing its duration.

\subsection{Duration of telecommuting days (telecommute)}

Telecommute referred to the maximum number of days that commuters worked from home in the aftermath of Hurricane Sandy. The starting point of the duration was Hurricane Sandy's arrival on October $29^{\text {th }}, 2012$. The days of telecommuting varied from 0 to 8 days and skewed to the left, with an average of approximately 1 day and standard deviation of approximately 2 days.

The extreme parameterization factor and the slope of the Weibull cumulative distribution

plot were $\delta=0.336$ (Table 2) and $P=\frac{1}{\delta}=2.98$, respectively. The Weibull model parameter P's value greater than 1 suggested that the hazard rate monotonically increased in duration, consistent with an interpretation that commuters were more likely to stop telecommuting as time passed.

Hypothesis 6 was rejected. The number of telecommuting days decreased by $2 \%$ [(1$\left.e^{-0.019}\right) \cdot 100$ ] per additional year of age, in contrast to our expectations. This may be because older commuters work at more advanced positions that require them to be present at work, or 
that they lack skills to telecommute effectively. Another potential explanation is that older commuters might have resided in areas where internet connectivity or electricity was disrupted so telecommuting was infeasible.

Table 2 indicates that telecommuting time increased by a factor of $1.008(\exp (0.008))$ per thousand dollars of income, supporting hypothesis 4 , and that the number of telecommuting days for individuals normally commuting during the peak hours decreased by 54\% [(1$\left.\left.e^{-0.617}\right) \cdot 100\right]$, supporting hypothesis 5a. Also as expected, those who had to deal with transportation disruptions prolonged their telecommuting time. Those who faced carpool restrictions at the Lincoln Tunnel, Brooklyn, Manhattan, Queensboro, and Williamsburg bridges increased their telecommuting duration by $63 \%\left(e^{0.493}\right)$, while telecommuting duration increased by $86 \%\left[\left(e^{0.623}-1\right) \cdot 100\right]$ for commuters who were affected by taxi policies for multiple independent riders and allowance of all for-hire vehicles to pick up passengers. Similarly, service disruptions on the New Jersey Transit bus and rail increased the telecommuting time for affected commuters by $42 \%\left[\left(e^{0.351}-1\right) \cdot 100\right]$.

Finally, the interaction term of the number of children younger than 15 years old in the household and the indicator variable of day care or school closure appeared highly significant. The commuters with one additional child whose school was closed telecommuted less days by a factor of $0.76\left(e^{-0.276}\right)$. Potentially, having more young children at home required spending more time with them, which might not have allowed the parents to work at all. While the number of young children as a stand-alone variable was insignificant, when accounting for school closure and the children (potentially) being at home, hypothesis $2 b$ was supported. The same reasoning holds for hypothesis $3 b$ which was effectively supported.

\subsection{Duration of alteration of commuting patterns (alteration)}

The reported days of commuting pattern changes ranged from 0 to 30 days with a mean of 6.7 days and a standard deviation of 7.4 days. The $P\left(\frac{1}{\delta}\right)$ shape parameter of the Weibull distribution was greater than 1 as shown in Table 2, indicating that the hazard monotonically increased with time. Commuters were more likely to return to their normal travel patterns as time passed.

Income was not significant in this model so hypothesis $4 b$ was rejected. The extensive disruptions to the transportation system may have affected everyone for the same duration, regardless of income. Similarly, gender, number of children in the household, school/daycare closures, peak period daily commuting, and home damages were not significant in this accelerated failure time model, therefore hypotheses $1 a, 2 a, 3 c, 5 c$, and 7 were not supported.

The duration of alteration for those affected by the gas purchase restriction policy increased by $27 \%\left[\left(e^{0.241}-1\right) \cdot 100\right]$, supporting hypothesis 8 . Looking at the descriptive statistics, gasoline purchase restrictions affected $50.4 \%$ of the sample and impacted post-Sandy commute patterns. The policy measure was used to ensure continuity of the fuel supply and discourage people from commuting by their personal automobile, but as a trade-off became a hurdle for commuters who encountered severe delays associated with long queues at the gas stations. The commute pattern alteration duration increased by $43 \%\left[\left(e^{0.359}-1\right) \cdot 100\right]$ for commuters who faced the New Jersey Transit bus and rail system disruptions. Although not related to hypothesis variables, longer travel times for the work-to-home trip under normal conditions prolonged the days of altered commute patterns by a factor of 1.004 per minute $\left(e^{0.004}\right)$. Longer commute times were associated with greater distance, as those two independent variables were significantly correlated. Commuters with longer commute times 
may have altered their commute patterns for a greater number of days due to a greater probability of encountering disruptions or encountering multiple disruptions.

\subsection{Application to Commuter Archetypes}

While we lack the necessary data to use the modeling results to estimate aggregate behavior across the entire population of commuters in the New York City metropolitan area, we can use the estimates from our sample to predict behavior for different kinds of individuals. For each dependent variable, we considered two hypothetical commuters. One has characteristics that make them particularly sensitive to disruption, and the other characteristics that make them less sensitive. For example, based on the significance and sign of the three travel variables indicated in the rightmost column of Table 2, we would expect an individual who normally has a long commute, and who was impacted post Hurricane Sandy by gasoline restrictions and by NJ transit network disruptions (hypothetical person X) to have more days of commute pattern alteration than an individual who normally has a short commute, and who was not impacted by gasoline or NJ transit disruptions (hypothetical person Y).

Table 3 shows the results of this prediction exercise, based on the parameters estimated in our models (we include only significant variables in our prediction equations and hold socioeconomic and demographic variables at their means). As implied from the above, hypothetical person $\mathrm{X}$ has a much longer time span of commute alteration (14 days) than hypothetical person Y (6 days). For our dependent variable indicating the number of days before commuters returned to a normal working schedule and location, returnnormal, hypothetical person $\mathrm{X}$ would have a telecommuting option under normal conditions and was affected by $\mathrm{NJ}$ transit disruptions, and hypothetical person $\mathrm{Y}$ would lack such an option and not have been affected by NJ transit disruptions. Table 3 shows that the more sensitive person $\mathrm{X}$ had a work schedule and location change almost fourteen times as long as a less sensitive hypothetical person Y. The difference in the additional commute time for home-to-work trips post Hurricane Sandy, commutedelay, between more sensitive and less sensitive commuters is also striking. Based on the significant coefficients in the model for this dependent variable in Table 2, those with normally long commutes who faced carpool bridge restrictions and transit users experienced commute delays more than five times longer than those with shorter commutes and automobile drivers not facing these restrictions.

\section{TABLE 3. Predicted durations for different hypothetical commuters}

\begin{tabular}{ccccc}
\hline $\begin{array}{c}\text { Hypothetical } \\
\text { Person }\end{array}$ & $\begin{array}{c}\text { returnnormal } \\
\text { (days) }\end{array}$ & $\begin{array}{c}\text { Commutedelay } \\
\text { (minutes) }\end{array}$ & $\begin{array}{c}\text { telecommute } \\
\text { (days) }\end{array}$ & $\begin{array}{c}\text { alteration } \\
\text { (days) }\end{array}$ \\
\hline $\mathrm{X}$ & 28 & 114 & 5 & 14 \\
$\mathrm{Y}$ & 2 & 25 & 1 & 6 \\
\hline
\end{tabular}

\section{CONCLUSIONS}

This paper used data from a survey of nearly 400 commuters in the New York City Metropolitan Area to determine the transportation disruption and socio-economic and demographic characteristics associated with the duration of travel changes for commuters in the aftermath of Hurricane Sandy. The four durations examined included (1) time to return to normal working schedule and location, (2) delay of commute time from home to work, (3) telecommuting duration, and (4) time of alteration of commuting patterns. These durations related to travel 
changes were modeled by using accelerated failure time modeling based on the Weibull distribution.

The significance of the independent variables differed across the four duration models, suggesting that the factors influencing commuters' decisions varied across different aspects of commuting. Notwithstanding this generalization, a few factors remained consistently significant in several of the models. For instance, the disruptions of the New Jersey Transit system prolonged the duration of the time to return to normal working schedules and locations, the duration of telecommuting, and duration of commuting pattern changes in the aftermath of Hurricane Sandy. Logically, the longer recovery time (Newman et al., 2012) required for New Jersey Transit commuters obligated them to adapt their behavior for a longer period of time. This result suggested a spatial characteristic of the disaster; potentially New Jersey commuters had to telecommute more days until the transportation system was restored. Based on the provided zip codes, out of the 397 respondents, 112 resided in and 77 worked in New Jersey. However, $5.3 \%$ of the commuters (21 out of 395) indicated that their commute or transportation was affected by service disruptions on the New Jersey Transit rail and bus system and 5 out of the 21 indicated that they telecommuted more than 5 days when the average telecommuting time was approximately one day.

Commuters who had a college degree were more likely to spend greater time before returning to their normal working schedules/locations. Greater normal commute time from work to home increased the duration of the delay of the commute trip and the length of commuting pattern alterations in the post-disaster phase. In terms of the transportation policies applied, gasoline purchase restrictions led to an increase in the duration of commuting patterns alterations. Carpool restrictions on certain bridges of the Metropolitan area's transportation network lead to an increase in the delay time of the daily home to work trip and increased the duration of the telecommuting time.

In terms of the specific hypotheses, we summarize the results as follows:

- Hypothesis 1: Women are more likely to have (a) longer commute alteration durations and $(b)$ lower home to work trip delays. The analysis did not support this set of hypotheses. Gender was not significant in any of the duration models, possibly due to conflicting effects when changes were aggregated into the commute change variable. The literature is inconsistent in the effect of gender on commute changes, and our results did not clarify this inconsistency.

- Hypothesis 2: The number of children in the household is (a) positively associated with the days of commute alteration and (b) negatively associated with the telecommuting duration. The results did not support the first part of this hypothesis, but they did support the telecommuting hypothesis when the number of children was interacted with school/day care closures. More children at home due to closures, particularly young children, would make it more difficult to telecommute and work at home.

- Hypothesis 3: Day care/school closure is positively associated with (a) work schedulelocation change duration, (b) telecommuting duration, and (c) commute alteration duration. The analysis did not support these hypotheses using the closure on its own. Day care/school closure appeared significant only when interacted with the number of children in the household for the telecommuting model, as discussed in hypothesis 2. 
- Hypothesis 4: Higher income is positively associated with (a) longer telecommuting time, (b) days of commuting alteration, and (c) work schedule-location change. The analysis supported hypothesis $4 \mathrm{a}$ but not $4 \mathrm{~b}$ and $4 \mathrm{c}$. Higher income jobs may be more likely to have telecommuting options, and commuters who earn more may be able to afford to prolong the duration of commuting pattern alteration. Even though income was not significant in the work schedule-location change model, the related variable indicating higher educational attainment was. This term was positively associated with the work schedule-location change.

- Hypothesis 5: Peak period return commute is (a) negatively associated with telecommuting duration, (b) positively associated with home to work delays, and (c) positively associated with commute alteration duration. The results supported hypothesis $5 \mathrm{a}$ but neither hypotheses $5 \mathrm{~b}$ nor $5 \mathrm{c}$. If the job had less flexibility, possibly indicated by a peak period return commute, telecommuting may not have been an option; thus the negative association. In terms of delays and alteration, the additional (temporary) service actions implemented by transit and transportation agencies may have helped mitigate the disruptions' effects.

- Hypothesis 6: Older commuters telecommute for a longer period than younger telecommuters. The analysis did not support a positive relationship between age and telecommute duration but rather a negative one; that is, older commuters appeared to have telecommuted fewer days. Perhaps older commuters held positions that required them to be present at their work locations or they preferred to be in-person rather than a virtual presence. Younger commuters may not have been able to work at all due to their work places' closure.

- Hypothesis 7: Having a damaged home is associated with longer durations of commuting changes. The results did not support this hypothesis. Damage to survey participants' residences did not have a significant impact on the duration of the alteration of commuting patterns. However, residence damages had a significant impact in prolonging work schedule changes, potentially due to dealing with home repairs.

- Hypothesis 8: Gasoline purchase restrictions are associated with an increase in the duration of commuting changes. The results supported this hypothesis. Since approximately $50 \%$ of the commuters indicated that they had to deal with gas restrictions and possibly shortages, the commute of this subsample likely was altered. The open ended questions in the survey about the hurricane impacts revealed long queues at gas stations, potentially increasing the duration of commute trip changes, such as mode or route alteration. The policy was applied on November 3, 2012 for New Jersey, five days after Hurricane Sandy struck, to mitigate potential gas shortages (Kaufman et al., 2012). New York City applied this policy on November 9, 2012, 11 days after Hurricane Sandy struck (Kaufman et al., 2012). The introduction of the policy on different days in the aftermath of Hurricane Sandy for the two neighboring states might have temporally spread the impact of this policy, prolonging the duration of the alteration of the commuting pattern, especially for those who commute from one state to another. 
The duration analyses can provide several insights to transport systems managers for recovery planning and operations in the wake of large-scale disruptions, particularly in the context of commuters' adaptability. First, the study implies that the transport mode used by a commuter under normal every-day commute conditions does not have an impact on the duration of commuter behavior changes in the face of a large scale, multiple mode disruption, even though it has a significant impact on the character of the changes themselves. Neither being a regular transit nor automobile user was significant in modeling the duration of the commute alteration. However, commuting by automobile was associated with decreasing delay durations, possibly underlining the extensive delays that alternative mode users had to face. Transit commuting was weakly associated with longer durations to return to normal work schedules. On the other hand, the types of disruptions that commuters experienced and the policies applied were significant in the duration models, implying that specific incidents such as the application of carpool restrictions and the prolonged duration of service unavailability for New Jersey Transit had a significant impact on the duration of the commute travel alterations. Especially considering the transit dependent population, multimodal response should be planned accordingly to accommodate a community's mobility needs. In addition, the timely response and recovery to the disruptions were significant. This consideration was underlined by the fact that New Jersey Transit disruptions had a significant impact on extending the duration of time to return to a normal working schedule, telecommuting, and commuting alteration. Lastly, the gasoline purchase policy prolonged alterations of commuting patterns, potentially pointing out the trade-off effect of such policy measures, especially on commuters who rely on their personal vehicles to conduct their commute trips. However, many transport system experts consider the gas purchase restriction policy essential in periods of crisis, because it aims at preserving fuel supplies needed to run personal automobiles.

\section{ACKNOWLEDGEMENTS}

Partial funding was provided by National Science Foundation Award 1313674, for which the authors are grateful. The content of this paper is solely the responsibility of the authors and does not necessarily express NSF's views.

\section{REFERENCES}

American Association for Public Opinion Research. 2015. Standard definitions: Final dispositions of case codes and outcome rates for surveys, 8th Ed., AAPOR, Oakbrook Terrace, IL.

Anastasopoulos, P., Haddock, J., Karlaftis, M., Mannering, F., 2012. Analysis of Urban Travel Times. Transportation Research Record: Journal of the Transportation Research Board 2302(-1), 121-129.

Ardekani, S.A., 1992. Transportation Operations Following the 1989 Loma Prieta Earthquake. Transportation Quarterly 46(2), 219-233.

Besser, L.M., Marcus, M., Frumkin, H., 2008. Commute Time and Social Capital in the U.S. American Journal of Preventive Medicine 34(3), 207-211. 
Blake, E.S., Kimberlain, T.B., Berg, R.J., Cangialosi, J.P., Beven, J.L. 2013. Tropical Cyclone Report: Hurricane Sandy (AL182012). http://www.nhc.noaa.gov/data/tcr/AL182012_Sandy.pdf.

Bloomberg, M.R., 2012a. Executive Order 164: Amendment of Prior Proclamation of a State of Emergency, in: The City of New York: Office of the Mayor (Ed.).

Bloomberg, M.R., 2012b. Executive Order No. 165 Emergency Evacuation and Re-Occupation and Transportation Order, in: The City of New York: Office of the Mayor (Ed.).

Bloomberg, M.R., 2012c. Executive Order No. 170 Emergency Order Regarding Sale of Motor Fuel to Vehicles, in: The City of New York: Office of the Mayor (Ed.).

Caruso, D.B., 2012. Sandy Gas Rationing: Post-Hurricane Challenges Continue As New Jersey And New York Recover From Storm, Huffington Post, U.S. ed.

Condon, B., Rothwell, S., 2012. Wall Street Back in Business After Hurricane Sandy Shutdown.

Crane, R., 2007. Is there a quiet revolution in women's travel? Revisiting the gender gap in commuting.

Journal of the American Planning Association 73(3), 298-316.

Crane, R., Takahashi, L., 2009. Sex Changes Everything The Recent Narrowing and Widening of Travel Differences by Gender. Public works management \& policy 13(4), 328-337.

Cutter, S.L., Boruff, B.J., Shirley, W.L., 2003. Social Vulnerability to Environmental Hazards. Social Science Quarterly 84(2), 242-261.

Cutter, S.L., Mitchell, J.T., Scott, M.S., 2000. Revealing the Vulnerability of People and Places: A Case Study of Georgetown County, South Carolina. Annals of the Association of American Geographers 90(4), 713-737.

Enarson, E., Fothergill, A., Peek, L., 2007. Gender and Disaster: Foundations and Directions, in: Rodriguez, H., Quarantelli, E.L., Dynes, R.R. (Eds.), Handbook of Disaster Research. Springer, New York, pp. 130-146.

Enarson, E., Morrow, B., 1997. A Gendered Perspective. Hurricane Andrew: Ethnicity, gender and the sociology of disasters, 52-74.

Fothergill, A., 1996. Gender, Risk and Disaster. International Journal of Mass Emergencies and Disasters 14(1), 33-56.

Fu, H., Wilmot, C.G., 2006. Survival Analysis Based Dynamic Travel Demand Models for Hurricane Evacuation. TRB Annual Meeting CD ROM.

Gigerenzer, G., 2006. Out of the Frying Pan into the Fire: Behavioral Reactions to Terrorist Attacks. Risk Analysis 26(2), 347-351.

Giuliano, G., Golob, J., 1998. Impacts of the Northridge Earthquake on Transit and Highway Use.

Journal of Transportation and Statistics(May), 1-20.

Gould, J., Zhou, J., 2009. A Commitment to Continue?: Comparing Women and Men Commuters Who Choose Transit Over Driving Alone, 4th International Conference on Women's Issues in Transportation. Transportation Research Board, Irvine, CA, pp. 154-162.

Gray, G.E., Roberts, J.E., Markowitz, J.E., 1990. Aftershock: Dealing with the Highway Crisis After the Loma Prieta Earthquake. TR News July-August, 3-8.

Harris, E.A., 2012. A Slow Return to Normal Skips the Gas Station, The New York Times, New York.

Hasan, S., Mesa-Arango, R., Ukkusuri, S., 2013. A random parameter hazard based model to understand the temporal dynamics of household evacuation timing behavior. Transportation Research Part C 27, 108-116. 
Hendrickson, C.T., Carrier, R.E., Dubyak, T.J., Anderson, R.B., 1982. Traveler Responses to Reconstruction of Parkway East (I-376) in Pittsburgh. Transportation Research Record 890, 33-39.

Hensher, D.A., Mannering, F.L., 1994. Hazard-based duration models and their application to transport analysis. Transport Reviews 14(1), 63-82.

Homeburger, W.S., 1990. The Loma Prieta Earthquake: What Happened to the Trip Makers? A Preliminary Report, Institute of Transportation Engineers 43rd Annual Meeting, Boise.

Hosmer, D.W., Lemeshow, S., May, S., 2011. Applied Survival Analysis: Regression Modeling of Time to Event Data, 2nd ed. Wiley-Interscience [Imprint].

Ito, H., Lee, D., 2005. Assessing the impact of the September 11 terrorist attacks on U.S. airline demand. Journal of Economics and Business 57(1), 75-95.

Jenkins, P., Renne, J.L., Kiefer, J., 2011. Gender Differences in Self-Reported Evacuation Experiences: Analysis of the City Assisted Evacuation Program During Hurricane Gustav, 46 ed. Transportation Research Board, pp. pp 127-133.

Johnston Anumonwo, I., 1998. Distance, race, and labor force participation: Implications for women of color, Women's Travel Issues: Proceedings from the Second National Conferences.

Juan, Z., Xianyu, J., Gao, L., 2011. Understanding Commuters' Daily Travel Time: Application of a Hazard-Based Duration Model, in: Wu, D.D. (Ed.), Modeling Risk Management in Sustainable Construction. Springer Berlin Heidelberg, pp. 379-386.

Kaufman, S., Qing, C., Levenson, N., Hanson, M., 2012. Transportation During and After Hurricane Sandy. Rudin Center for Transportation; NYU Wagner Graduate School of Public Service.

Kontou, E., Murray-Tuite, P., 2014. Commuter Travel Changes in Hurricane Sandy's Aftermath, 93rd Annual Meeting of the Transportation Research Board Washington, D.C.

Kontou, E., Murray-Tuite, P., Wernstedt, K. (2016). Commuter Adaptation in Response to Hurricane Sandy's Damage. Natural Hazards Review, 04016010.

Liu, S., Murray-Tuite, P., Schweitzer, L., 2012. Analysis of child pick-up during daily routines and for daytime no-notice evacuations. Transportation Research - A 46, 48-67.

Lopez-Rousseau, A., 2005. Avoiding the Death Risk of Avoiding a Dread Risk: The Aftermath of March 11 in Spain. Psychological Science 16(6), 426-428.

Mauch, M., Taylor, B.D., 1997. Gender, race, and travel behavior: Analysis of household-serving travel and commuting in San Francisco bay area. Transportation Research Record: Journal of the Transportation Research Board 1607(1), 147-153.

Meyer, M.D., 1985. Reconstructing Major Transportation Facilities: The Case of Boston's Southeast Expressway. Transportation Research Record 1021, 1-9.

Mokhtarian, P.L., Ye, L., Yun, M., 2009. Effects of Gender on Commuter Behavior Changes in the Context of a Major Freeway Reconstruction, 4th International Conference on Women's Issues in Transportation. Transportation Research Board, Irvine, CA, pp. 143-153.

Moore, J., Carrasco, J.-A., Tudela, A., 2013. Exploring the links between personal networks, time use, and the spatial distribution of social contacts. Transportation 40(4), 773-788.

Morrow, B.H., 1999. Identifying and mapping community vulnerability. Disasters 23(1), 1-18.

Newman, A., McGeehan, P., Yee, V., Chen, D.W., 2012. Hurricane Sandy: Covering the Storm, The New York Times. 
NJ Transit, 2012. NJ Transit Customers Encouraged to Avoid Delays, Take Free Service from Liberty State Park to Lower Manhattan: Free Parking, Shuttle Buses, Ferries to Battery Park.

Prager, F., Beeler Asay, G.R., Lee, B., von Winterfeldt, D., 2011. Exploring Reductions in London Underground Passenger Journeys Following the July 2005 Bombings. Risk Analysis 31(5), 773-786.

Pucher, J., Renne, J.L., 2003. Socioeconomics of Urban Travel: Evidence from the 2001 NHTS. Transportation Quarterly 57, 49-77.

Rosenbloom, S., 2006. Understanding Women's and Men's Travel Patterns, Research on Women's Issues in Transportation: Report of a Conference. Transportation Researchh Board: Washington, DC, pp. 7-28.

Rosenbloom, S., Burns, E., 1993. Gender differences in commuter travel in Tucson: implications for travel demand management programs.

Rosenbloom, S., Burns, E., 1994. Why working women drive alone: Implications for travel reduction programs.

Rubin, G.J., Brewin, C.R., Greenberg, N., Hacker Hughes, J., Simpson, J., Wessely, S., 2007. Enduring consequences of terrorism: 7-month follow-up survey of reactions to the bombings in London on 7 July 2005. The British Journal of Psychiatry 190, 350-356.

Sarmiento, S., 2000. Household, gender, and travel, Women's Travel Issues Second National Conference.

Smith, T.W. (2009). "A revised review of methods to estimate the status of cases with unknown eligibility." Rep. of the Standard Definitions Committee, American Association for Public Opinion Research, Oakbrook Terrace, IL.

Trotta, D., 2012. Sandy strengthens as nears U.S. coast; Wall Street shut, REUTERS.

U.S. Census Bureau, 2012. 2011 American Community Survey, American Fact Finder.

Washington, S., Karlaftis, M.G., Mannering, F.L., 2011. Statistical and Econometric Methods for Transportation Data Analysis. Taylor and Francis Group, Boca Raton, FL.

Weselcouch, M., 2013. Sandy's Effects on Housing in New York City. http://furmancenter.org/files/publications/SandysEffectsOnHousingInNYC.pdf

Zhong, M., Hunt, J.D., Lu, X., 2008. Studying differences of household weekday and weekend activities: a duration perspective. Transportation Research Record: Journal of the Transportation Research Board 2054, 28-36.

Zhong, M., Wu, C., Hunt, J.D., 2012. Gender differences in activity participation, time-of-day and duration choices: new evidence from Calgary. Transportation planning and technology 35(2), 175-190.

Zhu, P., 2013. Telecommuting, Household Commute and Location Choice. Urban Studies 50(12), 24412459.

Zhu, S., Levinson, D., Liu, H., Harder, K., 2009. The traffic and behavioral effects of the I-35W Mississippi River bridge Collapse, Annual Meeting of the Transportation Research Board. Transportation Research Board, Washington, D.C. 